\title{
PERSPECTIVAS ASSOCIATIVAS E CONHECIMENTO DO ENFERMEIRO REFERENTES À ABEn
}

Iraci dos Santos*

\begin{abstract}
RESUMO - Identifica as relações dos enfermeiros com a Associação Brasileira de Enfermagem (ABEn) no que se refere à participação, conhecimento e perspectiva. Revela que, na população estudada, $50 \%$ dos profissionais estão associados e que têm o conhecimento da entidade em nível "muito bom". Pretendem os enfermeiros que a ABEn realize pesquisas culturais e sociais, cursos e palestras em instituições e que utilize os meios de comunicação para se tornar mais conhecida.
\end{abstract}

\begin{abstract}
The work identifies the nurses' relations with the Brazilian Nursing Association concerning participation, knowledge and perspective. It shows that $50 \%$ of the professionals in the population studied are members of the association and have information about the organization in a level considered "very good". The nurses expect the association to carry on cultural and social researches, promote lectures and courses at institutions and resort to the media in order to get better known by its public.
\end{abstract}

\section{INTRODUC̣ÃO}

A história de uma associação profissional retrata as características da profissão e dos profissionais que lhe dão origem. Nota-se que o processo de iniciação, estabelecimento, as lutas, êxitos e até os fracassos de uma profissão estão intimamente ligados à sua Associação de Classe. Por assim dizer, se uma profissão é bem-sucedida e reconhecida na sociedade a que se destina, tal fato relfetir-se-á em sua Associação. Isto porque, assevera GERMANO (1984), o marco referencial, a ideologia e poder da profissão podem ser veiculadas aos profissionais pela sua Entidade de Classe. Do mesmo modo, a força, o poder de penetração e de reivindicação dos profissionais, só existem quando estes se unem, conjugam esforços e mantêm-se coesos num mesmo ideal. Se assim não fora, a existência de uma Associação profissional não seria um dos requisitos para que uma profissão pudesse integrar a Organização Internacional do Trabalho (OIT).

Entretanto, ha que se reconhecer que as pessoas, as profissões e as associações profissionais inexistem quando alienadas do processo cultural e histórico da humanidade, particularmente, do seu contexto nacio- nal. E, assim, neste momento de abertura política, de avanço cultural e social em que tudo é questionado e do qual todos querem fazer parte, observamos mudanças muito significativas em termos de direção, participação na estrutura e filosofia da Associação Brasileira de Enfermagem (ABEn). Antes, um pequeno grupo se mantinha e se revezava no poder; hoje, mais e mais enfermeiros, jovens em sua maioria, querem dele participar e decidir com suas novas idéias, o destino de sua profissão.

Recordam, hoje, os enfermeiros sócios ou não, que muitas lutas em prol da profissão foram enviadas e de iniciativa da ABEn, à execução do COFEn, conforme relata DOURADO (1985).

Conhecem seu objetivo, participam dos seus eventos e se beneficiam dos serviços prestados pela ABEn?

Refletindo-se sobre estas questões chega-se a outro problema de maior amplitude que é a própria perspectiva do enfermeiro em relação à $\mathrm{ABEn}$. $\mathrm{O}$ que espera este profissional de sua Associação de Classe?

Partindo do pressuposto de que as perspectivas dos enfermeiros correspondem as suas aspirações de desenvolvimento cultural e assistencial prometido pela

\footnotetext{
* Trabalho premiado: "60 anos da Associação Brasileira de Entermagem"

** Enfermeira do Instituto de Assistência dos Servidores do Estado do Rio de Janeiro. Docente da Faculdade de Enfermagem da Universidade do Rio de Janeiro.
} 
ABEn aos seus associados, o que deverá ser conhecido, discutido e avaliado pela classe a fim de que esta dele participe, este trabalho tem pois, como objetivos: - identificar o enfermeiro caracterizando-o segundo sua participação na ABEn;

- analisar o conhecimento do enfermeiro sobre a ABEn correlacionando-o à sua categoria social;

- relacionar as perspectivas associativas do enfermeiro de acordo com sua categoria social.

\section{LITERATURA}

Neste ano de 1986 quando a Associação Brasileira de Enfermagem completa 60 anos de existência recorda-se a sua história, suas lutas para o crescimento da profissão e sua afirmação junto às demais da área da saúde.

Iniciada em 1926, a ABEn, segundo documenta CARVALHO (1976), foi iniciativa de um grupo de enfermeiros recém-formados pela Escola de Enfermagem Ana Neri, que entendeu ser necessário ao progresso da profissão o surgimento de uma entidade para congregar os novos profissionais.

Confirmando este relato, GERMANO (1984) correlaciona a origem da $\mathrm{ABEn}$ à própria formação de enfermeiro no Brasil, ao dizer que a partir do seu objetivo inicial em 1929, nota-se a preocupação dos seus dirigentes com o progresso e educação dos enfermeiros, fundamentados nos princípios das Escolas Governamentais. Para alcançar tal finalidade, diz a autora, a ABEn criou em 1932, a "Revista Anais de Enfermagem" que serviu de porta-voz oficial desta entidade, passando-se, em 1955, a denominar-se Revista Brasileira de Enfermagem (REBEn), vindo até hodiernamente a plasmar, moldar, divulgar conhecimentos profissionais e, assim, unificando os enfermeiros do todo o território nacional.

Para GERMANO (1984) este serviço prestado pela ABEn aos enfermeiros visava o estabelecimento de uma moral homogênea, ou seja, uma única direção cultural e moral para a classe de enfermagem.

Desde o ano de 1947 a ABEn realiza Congressos Nacionais. O primeiro foi sediado em São Paulo e Edith Magalhães Fräenkel, Presidente da ABEn-SP saudou os congressistas enfatizando a união dos enfermeiros como fator principal do desenvolvimento da enfermagem.

Estes Congressos, portanto, constituem no entender de CARVALHO (1972) um instrumento para a profissionalização do enfermeiro pelo muito que contribuem para que as aspirações da profissão penetrem na consciência social e se convertam em fatos concretos. $\mathrm{E}$, assim, além de unir os enfermeiros, os Congressos de destinam às discussões dos interesses da classe, relatam CALDAS et alii (1982), analisando suas Recomendações de 1947 a 1981. Destacam estas autoras que desde 1955 recomenda-se a ABEn para o alcance de seus objetivos, a promoção intensa de campanha de recrutamento de sócios e para despertar o interesse pela Entidade a organização de programas educativos, cursos intensivos, conferências e programas recreativos a fim de reunir enfermeiros dispersos nas diversas Instituições.

Na atualidade, lê-se no Estatuto da ABEn (1976): “Capítulo I - Da Natureza, sede, foro e finalidades Art. 10. - A Associação Brasileira de Enfermagem (ABEn) sociedade civil sem fins lucrativos, que congrega os enfermeiros, fundada a 12 de agosto de 1926, sob a denominação de "Associação Nacional de Enfermeiras Diplomadas Brasileiras" é uma entidade de direito privado, de caráter cultural e assistencial e se rege pelas disposições deste Estatuto e do Regulamento Geral.

Art. 4 ?

I - congregar os enfermeiros e incentivar o espírito de união e cordialidade entre os membros da classe;

II - promover o desenvolvimento profissional dos associados e de outras categorias compreendidas no Serviço de Enfermagem;

III - promover o inter-relacionamento com associações nacionais, estrangeiras e internacionais visando o aprimoramento e a divulgação da enfermagem brasileira;

IV - divulgar trabalhos e estudos de interesse da enfermagem e manter um órgão oficial de publicação periódica;

$\mathrm{V}$ - colaborar com as autoridades governamentais, principalmente de educação e saúde, na solução dos problemas afetos à enfermagem e à saúde;

VI - colaborar com órgãos oficiais de enfermagem na defesa dos interesses da profissão;

VII - instituir e manter obra filantrópica destinada à assistência dos associados idosos, desvalidos ou necessitados de amparo;

VIII - zelar pelos direitos e interesses dos associados;

IX - colaborar com as escolas de enfermagem no desenvolvimento do espírito associativo entre os estudantes, promovendo sua participação nas atividades sócioculturais programadas;

$\mathrm{X}$ - colaborar para a melhoria da assistência à saúde do povo brasileiro".

Mais recentemente, ainda, atendendo à reivindicações da categoria, o referido Estatuto foi analisado, discutido e avaliado tendo sido aprovado, em Assembléia Extraordinária de Delegadas da ABEn, 21.4.1986, no Estado de São Paulo, o novo Estatuto da ABEn, o qual encontra-se em fase de trãmites legais para a sua aplicação pela Diretoria.

Entretanto, destaca-se neste novo instrumento legal o acréscimo sof rido no seu capítulo I - “(...) é uma 
entidade de direito privado, de caráter cultural, científico e assistencial (...)".

Nestes 60 anos de existência nota-se o prestígio que a ABEn goza entre os enfermeiros o qual aparece bem nítido na recente pesquisa realizada pelo COFEn-ABEn (1985), quando um elevado percentual de enfermeiros $(62,8 \%$, no Rio de Janeiro) informam estar filiados à ABEn, enquanto esta entidade assevera que seu percentual de sócios quites, oscila entre 20,4 a 35,5\%. Tal fenômeno, deduzem as pesquisadoras, demonstra 0 quanto os enfermeiros valorizam a ABEn, pois apesar de não estarem em dia com o pagamento da anuidade, se consideram sócios desta.

Todavia, relatam CALDAS et alii (1982), em 1973, no XXV CBEn, os enfermeiros ali congregados ao considerarem a existência de apenas $1 / 3$ destes profissionais em todo o país, como membros ef etivos da ABEn, recomendaram, na ocasião, que esta sociedade promovesse estudos visando a descoberta das causasreais do desinteresse dos enfermeiros por sua Associação de Classe.

E, ainda, até há dez anos atrás, constatava-se a preocupação dos enfermeiros com este problema, quando no XXVIII CBEn, afirmam CALDAS et alii (1982), os congressistas consideraram a importância da divulgação da ABEn entre os estudantes de enfermagem com vistas à futura adesão à Associação de Classe.

Sobre a finalidade da política da ABEn, ainda nessa investigação, os enfermeiros propõem: intensificar atividades de pesquisa e estabelecer entrosamento com os Serviços de Saúde, COFEn, CORENs, SINDICATOS e Universidades; sugerem, também, maior regularidade na edição da REBEn, realização de cursos, seminários e congressos e trabalho ininterrupto de conscientização quanto à importância de se filiar à ABEn.

E, assim, esta Entidade vem atingindo seu objetivo inicial de manter a classe de enfermagem unificada numa única direção cultural, ideológica e moral.

Ao situarem o enfermeiro na realidade social brasileira e, conseqüentemente, na realidade social de sua profissão, LIMA et alii (1979) buscaram definir, neste contexto, o seu compromisso. Afirmam as autoras que o compromisso social baseia-se nos interesses e valores cultivados pela pessoa.

Estudando aspectos fenomenológicos para fundamentar a Deontologia da Enfermagem, PEREIRA (1983) conclui que "a concretude desses valores está relacionada com a função ética do enfermeiro - realizarse como "Homo Humanus" - buscando conhecer as condições da existência humana e as possibilidades do ser para compreender e assistir aqueles que dependem de seus conhecimentos específicos, dedicação e consciência moral".

Referente a este assunto o COFEn, institue o Código de Deontologia de Enfermagem que reza em seus "Capítulo II, art. 8. - São deveres do enfermeiro:
- exercer sua atividade com zelo e proibidade e obedecer aos preceitos da ética profissional, da moral, do civismo e das leis em vigor, preservando a honra, o prestígio e as tradições da profissão; (...)

- Capítulo III, art. 20 - É dever do enfermeiro:

- pertencer, no mínimo, a uma entidade da classe, da jurisdição onde exerce sua atividade profissional; - apoiar as iniciativas que visam ao aprimoramento cultural e à defesa dos legítimos interesses da Classe. (Brasil, 1975)

Sendo assim, a atitude profissional do enfermeiro exige um compromisso ético e social demonstrável conforme exemplificam LIMA et alii (1979) quando este participa nas atividades dos órgãos de classe, assumindo os ideais, normas e metas da profissão.'

Supondo que a atuação de uma Entidade de Classe depende da participação ef etiva dos profissionais que a compõem recordam-se os pronunciamentos de CARVALHO (1972) quanto às atividades da ABEn a serem desenvolvidas no campo operacional do enfermeiro:

- defender a classe e seus interesses sócio-econômicos, zelar pelo alto padrão profissional, cooperar com as autoridades na solução dos problemas profissionais e/ou educacionais de enfermagem; as quais são confirmadas na declaração de CASTRO (1982) de que a ABEn além de operacionalizar sua finalidade, essencialmente cultural, sempre disciplinou o exercício da enfermagem e defendeu junto às autoridades de saúde e de educaçãeus direitos pertinentes à qualidade sistêncià̀s condições do seu desenvolvimento.

Assistência esta que SIMÕES (1980), recebendo contribuições da REBEn, principal veículo de divulgação da ABEn, assim define: "um conjunto de ações sistematizadas e desempenhadas pelo enfermeiro e demais elementos da equipe de enfermagem, de modo a colocar o assistido em condições de reassumir sua autonomia em questões de saúde".

Verifica-se, portanto, a grande responsabilidade que tem o enfermeiro e a ABEn sobre o destino da saúde da sociedade de seu país.

\section{METODOLOGIA}

Visando o estudo da atuação de uma Entidade de Classe, o conhecimento e reações a estas apresentados pelo grupo social que a compõe, escolheu-se para a realização da pesquisa o método descritivo e a técnica de investigação social.

A população alvo constitui-se de 6.473 enfermeiros inscritos no COREn-RJ, segundo publicação do COFEn-ABEn (1986). Na seleção de sua amostra considerou-se a Tabela de dimensionamento da Fundação SESP, que prevê o estudo com $11 \%$ da população citada. Sendo assim, a amostra selecionada constou de 708 enfermeiros sediados no Estado do Rio de Janeiro no período de maio a junho de 1986. Justifica- 
se deste modo, o critério de quantidade adotado na seleção da amostra. Referente ao critério de qualidade, considerou-se que o fenômeno, objeto do estudo, teve seu início no Estado do Rio de Janeiro, em 1926 e até hoje nele existe em alta intensidade, por ser este um dos maiores centros populacionais, comerciais e culturais do Brasil, ocupando, inclusive e portanto, o segundo lugar do número de população de enfermagem cadastrada pelo COFEn no ano em curso.

Isto posto, foram investigados 366 enfermeiros que foram encontrados exercendo a enfermagem nas instituições governamentais e particulares, de ensino, hospitalares, ambulatoriais e de saúde pública. Condicionou a redução da amostra inicial o fato de que existem enfermeiros recém-formados inscritos no COREn (possuem franquia provisória) não atuando, ainda, na profissão; ressai também, o número de licenciados, aposentados, exercendo outra profissão e/ou nenhuma, gozando férias e, fato comprovado nesta pesquisa, atuando em mais de uma Instituição. Sendo assim e considerando-se a exigüidade do tempo para realizar a pesquisa, analisou-se apenas os questionários imediatamente após sua entrega.

\section{1 - Variáveis, Instrumento e Estratégia para a coleta de dados.}

Estudaram-se as seguintes variáveis que compreendem a problemática:

- independente - categoria social relativa à ABEn;

- dependentes

- faixa etária, tempo de exercício profissional e área de atuação;

- modalidade de pagamento de anuidade da ABEn, motivos para não se associar à ABEn;
- conhecimento sobre: objetivo, serviços prestados e veículos de divulgação da $\mathrm{ABEn}$;

- opinião sobre o recrutamento de sócios;

- sugestões para dinamizar a ABEn;

- meios de popularizar a ABEn;

- participação em eventos promovidos pela ABEn;

- recebimento de publicações da ABEn;

- freqüência em que os serviços da $A B E n$ devem ser prestados;

- opinião sobre a atuação da ABEn na sociedade e na classe de enfermagem.

Compõe o Instrumento de Coleta de Dados um questionário contendo 17 questões de múltipla escolha que agrupam as variáveis do estudo e foram classificadas conforme os seguintes assuntos:

- identificação da amostra (3 questões);

- participação na ABEn (3 questões);

- conhecimento sobre a ABEn (3 questões);

- perspectivas associativas (8 questões).

Para a coleta de dados contou-se com a colaboração de colegas enfermeiros que distribuiram os questionários em seus locais de trabalho no período de maio a junho de 1986, nos horários da manhã, tarde e noite.

\section{2 - Critério de avaliação das variáveis}

Tendo em vista a descrição de um fenômeno social, envolvendo reações e opiniões de pessoas, as variáveis foram tratadas estatisticamente, apenas, pela freqüência absoluta e relativa das respostas obtidas, analisando-se, por conseguinte, sua predominância.

As questões sobre o conhecimento relacionado à $\mathrm{ABEn}$ foram avaliadas atribuindo-se 1 (um) ponto para cada acerto, nas três questões propostas, ficando o critério assim, definido:

\begin{tabular}{l|c|l}
\hline \multicolumn{1}{c|}{ CONCEITO } & VALOR & \multicolumn{1}{c}{ SIGNIFICADO } \\
\hline Muito bom & 3 & $\begin{array}{l}\text { Acertou as três questões sobre objetivo, serviços prestados e veículos } \\
\text { de divulgação da ABEn. }\end{array}$ \\
\hline Bom & 2 & Acertou duas questões propostas. \\
\hline Regular & 1 & Acertou apenas uma das questões propostas. \\
\hline Péssimo & 0 & Errou todas as questões propostas. \\
\hline
\end{tabular}

\section{RESULTADOS E DISCUSSÃO}

Foram investigados 366 enfermeiros obtendo-se os seguintes resultados concernentes à sua participação na $\mathrm{ABEn}$ enquanto categoria social: a maioria, 188 (51,37\%), de enfermeiros não são sócios desta entida- de e, $178(48,63 \%)$, dela participam como sócios. Observando-se que a diferença existente entre estas categorias é insignificante $-2,74 \%$, confirma-se o esforço que a ABEn vem desenvolvendo há 60 anos, para congregar os enfermeiros nos ideais e interesses da Classe, por ela veiculados, segundo GERMANO 
(1984). Entretanto, há que se considerar as aspirações dos enf ermeiros relacionadas a afirmação de sua identidade o que se reflete na luta pela conquista do espaço e autonomia profissionais já que a maioria investigada não aceita o direcionamento da $\mathrm{ABEn}$.

Correlacionando-se categoria social e idade dos enfermeiros, nota-se que há predominância, 50 (28,09\%), de sócios na faixa etária de 30 a 36 anos enquanto os não associados, $66(35,10 \%)$ estão na idade de 23 a 29 anos. Verifica-se, portanto, que a maioria de não societários pertence ao grupo jovem, cu jo amadurecimento vem ocorrendo numa época de abertura política anos 80/86 - a qual deu oportunidade a reivindicações de independência e livre pensar em termos culturais e profissionais.

Referente ao tempo de exercício profissional e categoria gregária dos enfermeiros investigados, ressaltam-se os associados, $74(41,58 \%)$ exercendo a profissão há mais de 12 anos; enquanto os não sócios, $70(37,24 \%)$, atuam na enfermagem apenas de 1 (um) a 6 (seis) anos. 0 fato de a maioria de sócios ser mais experiente na profissão pode indicar um maior conhecimento sobre as necessidades e interesses da classe e/ou conformação aos ideais convencionados. Por outro lado o grupo jovem que não é membro da Entidade carece de mais informações e/ou convicções para se integrar nas lutas pelo desenvolvimento profissional conforme a Recomendação do XXVIII CBEn, analisada por CALDAS et alii. 1982.

Salienta-se, ainda, o grande número de sócios, 28 (15,73\%) e não sócios, 21 (11,17\%), que não responderam a esta questão. $O$ fato pode representar uma necessidade dos enfermeiros não se comprometerem ao indicar o tempo em que uma maior contribuição poderia ser dada ao crescimento da profissão?

Concernente à área de atuação dos enfermeiros congregados e/ou não sócios da $\mathrm{ABEn}$, dintinguese a alta freqüência, 144 (76,60\%) dos últimos na área hospitalar. Ressalta-se, também, a supremacia dos sócios na área de ensino, considerando-se o somatório das freqüências de $33(18,54 \%)$ e $48(29,97 \%)$ nas áreas de ensino e ensino/hospitalar, respectivamente, que é su perior à da área hospitalar, isoladamente - $79(44,40 \%)$.

Recorda-se, neste caso, que a criação da ABEn, foi iniciativa das primeiras enfermeiras diplomadas neste país, ou seja, surgiu de uma necessidade sentida na área de ensino. Sua origem, portanto, está intimamente ligada à Escola de Enfermagem Ana Neri, segundo relato de CARVALHO (1976). Seu objetivo inicial era congregar as ex-alunas da E.E.A.N., entretanto, diz a autora, verificando-se o imperativo de fortalecer a nova profissão, a Entidade foi aberta à diplomadas de outras escolas.

Assim, o fenômeno aqui identificado reforça a influência da origem da $\mathrm{ABEn}$ quanto à primazia de atendimento ao grupo de educadores em enfermageñ
Questiona-se a predominância de não sócios da ABEn na área hospitalar. Lembrando-se que este grupo representa a maioria de jovens (23 a 29 anos) profissionais de enfermagem, infere-se que o fato pode significar uma reação normal dos jovens ditada por seu desejo de independência, no caso, de seus prováveis antigos professores; ou, um anseio natural por coisas novas, avanços tecnológicos que são muito encontrados na área hospitalar, os quais estariam sobrepujando os ideais de progresso científico e cultural propostos pela ABEn. Ou, ainda, a sobrecarga de trabalho advinda da área hospitalar não permite o gregarismo destes profissionais? Recorda-se, neste caso, a conclusão de PEREIRA (1983) sobre a fundamentação da Deontologia de Enfermagem, a exemplificação de LIMA et alii (1979) relativa à atitude profissional do enfermeiro e o cumprimento do Capítulo III, art. 20 do Código de Deontologia, determinado pelo COFEn. (Brasil, 1975).

Outrossim, há muito que se refletir sobre esta questão. Deve a ABEn buscar este grupo jovem nos seus locais de trabalho, divulgar o objetivo e necessidades para o crescimento da pesquisa; ou esta Sociedade deve ser composta apenas pelos que nela acreditam e querem lutar por aquilo que julgam ser os interesses da classe?

Para se constatar o número real de membros e não sócios da $\mathrm{ABEn}$ investigou-se como estes ef etuam o.seu pagamento da anuidade à Instituição. Nota-se que, 146 $(80,02 \%)$, atendem o Regulamento da ABEn (1976) ao quitarem a anuidade todos os anos; todavia, um número significativo, 32 (17,98\%), de enfermeiros consideram-se sócios desta apesar de só pagarem a anuidade, eventualmente, quando participam de Congressos/Jornadas e Encontros. Sabem estes enfermeiros que a $\mathrm{ABEn}$ só considera como sócio quite aquele que paga sempre a anuidade? Neste caso como a ABEn classifica os $55(29,25 \%)$ não associados, que lhe pagaram anuidade, eventualmente, como condição obrigatória para participar dos Congressos por ela promovidos? Tal fenômeno já discutido na pesquisa COFEnABEn, ao se avaliar o prestígio que tem para os enfermeiros esta última Entidade.

Quanto aos motivos apresentados para não se associar à ABEn, destaca-se a freqüência de, $83(44,15 \%)$, para "Falta de posicionamento da ABEn nos interesses da classe". Revelando-se que a ABEn sempre lutou em defesa da classe conforme declara CASTRO (1982) e o fato de este motivo ter sido assinalado por não sócios, indaga-se: os interesses da classe para este grupo são diferentes daqueles do grupo associado?

Sobrepõe-se, ainda, a alta freqüência, 69 (36,71\%), de "outros" motivos que foram especificados pelos enfermeiros: desconhecimento dos objetivos da ABEn, falta de tempo, desinteresse, falta de atuação sóciocultural da ABEn, falta de democratização no acesso à Diretoria e desconhecimento do local para a inscrição.

Rev. Bras. de Enf., Brasília, 40(4), out./dez., $1987-2: 37$ 
Questionando-se os enfermeiros, segundo sua categoria social, sobre assuntos relativos ao trabalho desenvolvido pela $\mathrm{ABEn}$, tais como objetivo da Instituição, serviços prestados aos membros e veículos de divulgação, constatou-se que os associados, 178 (100,00\%), obtiveram maior freqüência de acertos em todas as questões, em relação aos não sócios, 188 (100,00\%), não sendo, entretanto, muito significativa esta diferença. A predominância, 165 (92,69\%), de acertos obtida pelos sócios é referente ao conhecimento sobre serviços prestados pela ABEn. Este fenômeno repete-se entre os não membros que alcançaram a frequiência de 142 $(75,53 \%)$.

Verifica-se que a maioria dos enfermeiros, independentemente da categoria social; conhecem objetivo, serviços e meios de divulgação da . ABEn. Entretanto, lembrando a tabela anterior, deve-se refletir por que os não sócios apontam como motivos da não associação o desconhecimento dos serviços prestados pela Entidade e falta de posicionamento desta nos interesses da Classe.

Na avaliação do conhecimento dos enfermeiros sobre a ABEn, observa-se que este foi conceituado, predominantemente, como "muito bom" para 135 $(75,84 \%)$ sócios e $100(53,20 \%)$ não associados Revela-se todavia a atribuição dos conceitos "regular" e “péssimo" para 33 (17,55\%) e 30 (15,96\%), não sócios respectivamente. Considerando que o conceito "muito bom" seria atribuído ao acerto das três perguntas sobre o objetivo, serviços e veículos de divulgação da ABEn, salienta-se a atribuição deste para a maioria de não associados. Confirma-se, desse modo, a citação do COFEn-ABEn sobre o fato de que os enfermeiros acreditam que esta última entidade lhes confere "Status". Sendo assim, apesar de não se associarem, procuram adquirir conhecimentos sobre esta instituição.

Relacionada à opinião dos enfermeiros sobre o recrutamento de sócios para a ABEn, uma supremacia de $120(63,83 \%)$ não associados responderam que não se deve recrutar, contradizendo as recomendações de CBEn, conforme CALDAS et alii (1982) e resultados da pesquisa eleborada por COFEn-ABEn (1985), enquanto, 93 (53,94\%) sócios opinaram favoravelmente.

Entre as sugestões apresentadas por associados e/ou não para o recrutamento de sócios encontram-se: divulgar mais os serviços e objetivo da ABEn nos locais de trabalho dos enfermeiros, promover cursos $\mathrm{e}$ palestras, promover maior participação dos estudantes e visitas da Diretoria da ABEn aos hospitais, tornar as atividades mais participativas, maior pòsicionamento da ABEn nas lutas da Classe e realizar movimentos culturais dentro das Instituições. Confirmandose conseqüentemente, os relatos de CALDAS et alii (1982).

Quanto às sugestões para dinamizar a ABEn se deve ressair a predominância de "desenvolver pesquisas culturais e sociais sobre a categoria" apresentada outrossim por membros e não associados - $116(65,16 \%)$ e 116 (61,70\%), respectivamente. À seguir, 87 (48,87\%) sócios e $76(42,42 \%)$ não societários indicam "integração com movimentos sociais". O fenômeno leva o imperativo de que a Diretoria da ABEn deve refletir sobre o alcance de sua finalidade - "promover o desenvolvimento cultural e assistencial" a qual está expressa em seu Estatuto aprovado há dez anos atrás. Entretanto, deve-se ressaltar a contribuição, citada por CASTRO (1982), que a ABEn vem of erecendo aos seus associados já há 60 anos (Ver Tabela 10).

Seguem-se as "outras" sugestões apresentadas pelos enfermeiros para dinamizar a ABEn: promover entrosamento com enfermeiros e hospitais, promover reuniões científicas, estudos e reciclagens, posicionamento político-partidário, maior participação nos campos operacionais e of erta de bolsa de estudo para pesquisa. Verifica-se, deste modo, que os enfermeiros reivindicam da ABEn uma maior participação cultural, técnica e científica no seu campo operacional. Fato sugestivo de que a $A B E n$ não vem desenvolvendo as atividades explicadas por CARVALHO (1976), constantes do seu programa de trabalho, junto ao campo operacional do enfermeiro.

Relacionados aos meios de popularizar a ABEn, percebe-se que os sócios e/ou não - $366(100,00 \%)$, almejam o alcance do próprio objetivo desta Sociedade o qual pode ser operacionalizado em "promover cursos e palestras dentro das Instituições" que foi assinalado numa freqüência majoritária de 218 (59,56\%). Observa-se, ainda, que a maioria, 204 (59,56\%), dos enfermeiros sugerem que a $\mathrm{ABEn}$, utilize com freqüência os meios de comunicação (TV, Rádio, Jornal e outros). Indaga-se: seria este o melhor recurso para que a profissão seja mais conhecida na sociedade? Ressaltase o meio "fortalecer os movimentos sindicais" apontado numa freqüência de $108(29,50 \%)$. 0 fenômeno indica que a ABEn deve se envolver com questões salariais e de mercado de trabalho. Sendo o Sindicato do Município do Rio de Janeiro, notoriamente, atuante, por que sobrecarregar a ABEn com tal atividade? Todavia, revela-se que, $18(4,91 \%)$, pesquisados não responderam sobre os meios de popularizar a ABEn. Questiona-se: os enfermeiros são contrários à popularização da sua Entidade de Classe ou não têm interesse em contribuir com respostas, para o seu crescimento?

Analisou-se a freqüência da participação dos enfermeiros nos eventos da ABEn, segundo a categoria social, relatando-se, aqui, apenas a predominância observada. Referente aos "Congressos" os enfermeiros assinalaram que deles participam "às vezes", numa freqüência de 98 (55,05\%) e $62(32,97 \%)$ para sócios e não sócios, respectivamente. Das "Jornadas e Encontros" os associados participam "às vezes" numa freqüência de $121(67,97 \%)$ e, igualmente, os não sócios, na freqüência de $85(45,21 \%)$.

Considerando que os Congressos são promovidos anualmente e correspondem a uma aspiração da cate- 
goria, conforme já ressaltava Amália C. de Carvalho no XXV CBEn, ABEn (1982), questiona-se o motivo dos membros da $\mathrm{ABEn}$ deles não participarem mais freqüentemente. Outrossim, é significativa a participação dos não sócios, mesmo considerando a freqüência“ "às vezes". Entretanto, há grande aceitação dos enfermeiros por este evento promovido pela ABEn. Infere-se que este fenômeno representa uma necessidade de desenvolvimento cultural e não somente profissional. Isto porque o desenvolvimento técnico-científico poderá ser obtido através das "Jornadas e Encontros" que são realizados mais freqüentemente e em ãmbito estadual e/ou regional, observando-se aí a grande participação de, $85(45,21 \%)$, dos não associados. Salienta-se destes resultados a não participação dos sócios em "Reuniões e Assembléias" a qual foi predominantemente assinalada - 68 (38,20\%). Se os societários não discutem e decidem em sua Sociedade, os problemas e interesses de sua profissão, como podem reivindicar um maior posicionamento desta nas questões sociais?

Coube ao evento "Eleições" a única freqüência "sempre" assinalada pelos sócios - 87 (48,87\%). Verifica-se a existência de um grupo sempre preocupado com o destino de sua Associação. Releva-se, também, que $8(4,25 \%)$, não sócios "sempre" comparecem às "Eleições" da ABEn. Como a Entidade explica estéltimo fenômeno? Acredita-se que para se esclareceesta questão, deve a ABEn redefinir o termo "sócio" uma vez que existem muitos "não sócios" que participam de todos os seus eventos.

Referente a predominãncia da freqüência em que as publicações da $\mathrm{ABEn}$ são recebidas pelos enfermeiros, nota-se que a maioria, $98(55,05 \%)$, de membros recebem 'semprè' a Revista Brasileira de Enfermagem (REBEn). Encontrando-se, 7 (3,72\%) não associados que são "semprè' beneficiados com a REBEn, pergunta-se: são estes não sócios que, também, participam "às vezes" dos "Congressos", considerados pela ABEn como sócios? Tal questionamento é condizente com o fato de que, $42(23,59 \%)$ não associados recebem "às vezes" o "Informativo ABEn", enquanto os sócios, 48 (26,96\%) igualmente o recebem na mesma intensidade. Observa-se que o "Noticiário" é "sempre" recebido por $78(43,28 \%)$ membros. Lembra-se que este veículo é publicado e distribuído pela Seção da $A B E n$, enquanto o "Informativo" e a "Revista" são de responsabilidade do Órgão Central. Infere-se deste fato que a ABEn vem atingindo seu objetivo de desenvolvimento cultural divulgando os trabalhos técnicos-científicos realizados por enfermeiros os quais têm contribuído para a afirmação do poder e ideologia da prof issão, que assevera GERMANO (1984) e, também, para a validação da terminologia profissional defendida por SIMÕES. (1980)

Analisando-se a predominância com que os serviços devem ser prestados pela $\mathrm{ABEn}$, na opinião dos enfermeiros, constatou-se que apenas as "Reuniões sociais" devem ser realizadas "às vezes" numa freqüên- cia de $71(39,88 \%)$, para sócios e 64 (34,04\%) para não sócios. Os serviços tais como: cursos, ciclo de debates, programas culturais e recreativos, conferências sobre assuntos comunitários, convênios com creches, entrosamento com Entidades de Classe, assessoria sobre trabalhos científicos e Revista científica cujos trabalhos independam de apresentação em Congressos, para serem publicados, na opinião de sócios e não sócios devem "sempre" ser prestados pela ABEn. Ressalta-se a supremacia da freqüência para realização de "cursos" apontada por $148(83,14 \%)$ membros e 137 $(72,87 \%)$ não sócios. Segue-se a preferência por "assessoria sobre trabalhos científicos", indicada por 131 $(73,59 \%)$ sócios de $126(67,02 \%)$ não associados. Denota-se, portanto, o anseio dos enfermeiros por seu crescimento técnico científico, fato evidenciado na proposta de publicação de "Revista científica cujos trabalhos independam de apresentação em Congressos", assinalada por $118(66,29 \%)$ sócios e $116(61,70 \%)$ não sócios e, também, quanto ao "Ciclo de Debates" indicado nas freqüências de 130 (73,03\%) e 91 (48,40\%) para os membros e não associados, respectivamente. Deduz-se, deste modo, que o desenvolvimento técnico-científico é valorizado pelos enf ermeiros, razão pela qual se interessam pelos citados serviços da ABEn, assumindo assim um compromisso social com a classe e a profissão, conforme analisa LIMA et alii (1979).

A menor freqüência de indicações de serviços a serem prestados pela $\mathrm{ABEn}$ é relativa à "Convênio com Creches". Revela-se que este serviço representa uma novidade a ser introduzida numa entidade de classe de enfermagem. Considerando a contribuição devida a um grupo predominantemente feminino e numa faixa etária (ver Tabela 2) sexualmente produtiva, justifica-se a opinião da maioria dos associados de que o referido serviço deve ser prestado pela ABEn, "sempre", nas freqüências de $95(53,37 \%)$ e 88 (46,80\%) para sócios e não sócios, respectivamente.

No que diz respeito à atuação da $\mathrm{ABEn}$ na Sociedade e na classe de enfermagem, observa-se que 90 $(50,56 \%)$ membros e 87 (46,27\%), não associados ressaltaram que"s sempre é questionado pelos enfermeiros o posicionamento desta Entidade frente aos problemas sociais. Salienta-se, portanto, uma maior cobrança da postura da ABEn na Sociedade, por parte de seus próprios associados.

Referente à penetração da ABEn na classe de enfermagem a maioria 101 (53,72\%), de não sócios e 95 $(53,57 \%)$ de sócios indicou que tal fato é "às vezes" aceito pelos enfermeiros. Infere-se, neste caso, que a ABEn é mais aceita pelos não associados, confirmandose a pesquisa do COFEn-ABEn (1985) sobre o prestígio tradicional da referida Entidade na classe profissional.

\section{CONCLUSÃo E SUGESTÕES}

A amostra pesquisada revelou que os enfermeiros são equivalentes quanto à sua categoria social relati- 
va a ABEn. Sócios, 178 (48,63\%) e não sócios, 188 $(51,37 \%)$ representam um grupo jovem que atua na profissão de 1 a 12 anos e predominantemente na área hospitalar. Conservando a origem da ABEn, a supremacia de seus membros exerce a docência de enfermagem.

A grande maioria de sócios e a maioria de não sócios têm "muito bom" conhecimento sobre a ABEn, sendo a questão concernente a serviços, a que obteve maior número de acertos. Releva-se, todavia, que 66 $(33,51 \%)$ não sócios possuem conhecimento entre regular e péssimo.

São perspectivas associativas dos enfermeiros: dinamizar e popularizar a ABEn e propõem que esta realize, predominantemente, pesquisas culturais e sociais sobre a categoria, cursos e palestras dentro das Instituições, tornando, assim, a enfermagem mais conhecida, utilizando, inclusive, os meios de comunicação tais como $\mathrm{TV}$, rádio, jornais e outros.

Os enf ermeiros, geralmente, participam dos eventos promovidos pela $\mathrm{ABEn}$, são beneficiados com suas publicações e reivindicam a esta entidade que intensifique a sua prestação de serviços, inclusive a assistência aos sócios.

Os associados questionam mais o posicionamento da ABEn frente aos problemas sociais enquanto a maioria de não sócios aceitam a penetração desta classe de enfermagem.

Considerando qir $\therefore$ A $\mathrm{ABEn}$ vem prestando relevantes serviços comernentes ao desenvolvimento técnico, científico e cultural da enfermagem sugere-se à esta entidade que:

- reaplique esta pesquisa em âmbito nacional haja vista as características e diferenças regionais da população alvo;

- avalie as necessidades de desenvolvimento cultural do enfermeiro, visando o atendimento das aspirações deste profissional;
- reestruture suas comissões de trabalho, favorecendo, assim, o alcance de suas finalidades;

- elabore um plano de ação para atender as novas perspectivas associativas dos enfermeiros identificadas neste trabalho.

\section{REFERÊNCIAS BIBLIOGRÁFICAS}

1. ABEn. Estatuto da Associação Brasileira de Enfermagem. Rio de Janeiro, 1976.

2. 33 anos do Congresso Brasileiro de Enfermagem. Re trospectiva. Brasília, 1982.

3. BRASIL. Leis, Decretos,etc. Código de Deontologia de Enfermagem. Brasília, COFEn, s.d. (Aprovado pela Resolução COFEn - 9, 1975).

4. CALDAS, Nalva P. et alii. Recomendações dos Congressos Brasileiros de Enfermagem. 1947-1981. Estudo Analítico. Rio de Janeiro, 1982.110 p.

5. CARVAlHO, Amália Correia de. Política de trabalho da Associação Brasileira de Enfermagem. Revista Brasileira de Enfermagem, Rio de Janeiro. 25(1-2):145-52. Jan/Abr. 1972.

6. CARVALHO, Anayde Correia. Associação Brasileira de Enfermagem. 1926-1976. Brasília, ABEn, 1976. 514 p. $514 \mathrm{p}$.

7. CASTRO, Ieda Barreira e. O papel social do enfermeiro: realidade e perspectivas de mudança. In: Congresso Brasileiro de Enfermagem, 34, Anais... Porto Alegre, 1982.

8. COFEn. Normas e Notícias. Rio de Janeiro, v. (9) n.1, 1986.

9. COFEn-ABEn. Força de Trabalho em Enfermagem. Rio de Ja neiro, 1985. v.1. 236 p.

10. DOURADO, Haydée G. Editoriais. Revista Brasileira de Enfermagem, Brasília 28(2); abr/jun. 1985.

11. GERMANO, Raimunda M. Educação e ideologia da Enfermagem no Brasil. Rio de Janeiro, Cortez, 1984. 118 p.

12. LIMA, Maria Lucia F. et alii. O enfermeiro e seu compromisso social. In: Congresso Brasileiro de Enfermagem, 31, Anais... Brasília, 1979.

13. PEREIRA, Araci Carmen. $O$ 'Ethos' da Enfermagem - Aspectos fenomenológicos para uma fundamentação da deontologia de Enfermagem. Rio de Janeiro, 1983.

14. SIMÕES, Noemia. Contribuição a o estudo da terminologia básica de Enfermagem no Brasil - Taxionomia. Rio de Janeiro, UFRJ, Escola de Enfermagem Ana Neri, 1980, 204 p. Diss. Mestr. 